\title{
VISIONES DEL PARAGUAY. LAS «REPRESENTACIONES DEL PASADO» EN LA REVISTA DEL INSTITUTO PARAGUAYO
}

\section{VISIONS OF PARAGUAY. THE «REPRESENTATIONS OF THE PAST» IN THE JOURNAL OF THE PARAGUAYAN INSTITUTE}

\section{Matías Borba Eguren ${ }^{1}$}

Enviado: $27 / 07 / 2020$

Aceptado: $28 / 11 / 2020$

Resumen: En 1895, en Asunción, se fundó el Instituto Paraguayo. Nucleados allí, la Generación del 900 o los Novecentistas conformaron un espacio propicio para el desarrollo intelectual del país. En 1896 comenzó a publicarse la Revista del Instituto Paraguayo, siendo una herramienta fundamental para la difusión, debate e intercambio de la producción y los intereses de estos intelectuales. El presente artículo se propone analizar las "representaciones del pasado" - categoría tomada de Paul Ricouer (2004) y Fabio Wasserman (2008) - que pueden hallarse en esta publicación. Bajo un análisis cualitativo y cuantitativo, se identifica cual es la época del pasado paraguayo que más abordan los artículos relevados, así como las posturas teórico-metodológicas detrás de estos.

Palabras clave: Revista del Instituto Paraguayo; Instituto Paraguayo; representaciones del pasado; Novecentismo.

Facultad de Humanidades y Ciencias de la Educación, Universidad de la República (Uruguay). Correo de contacto: matungo05@hotmail.com 
Abstract: In 1895, in Asunción, the Instituto Paraguayo was founded. Nucleated there, the Generación del 900 or the Novecentistas formed a favorable space for the intellectual development of the country. In 1896 the Revista del Instituto Paraguayo began to be published, being a fundamental tool for the dissemination, debate and exchange of the production and interests of these intellectuals. This paper aims to analyze the "representations of the past" - category taken from Paul Ricouer (2004) and Fabio Wasserman (2008) - that can be found in this publication. Under a qualitative and quantitative analysis, I identify which is the most studied period of the Paraguayan past in the examined articles, as well as the theoretical-methodological postures behind them.

Keywords: Revista del Instituto Paraguayo; Instituto Paraguayo; representations of the past; novecentismo. 


\section{Introducción.}

Con el fin de la Guerra de la Triple Alianza, y bajo la tutela de Argentina y Brasil, los sectores políticos paraguayos afines a los aliados - gran parte exiliados en Buenos Aires, y que ahora retornaban al territorio -, condenaron a los gobiernos anteriores - Gaspar Rodríguez de Francia, Carlos Antonio López, Francisco Solano López -, acusándolos de tiránicos y despóticos. La nueva política liberal - ahora en el gobierno, y con la urgencia de regenerar un país arruinado económico, político, cultural y socialmente -, buscó olvidar el pasado y comenzar un nuevo Paraguay "liberado" de sus pecados. Para eso apeló a construir un nuevo orden que llevara la "paz" y la "civilización" al territorio.

En este proceso, la Historia jugó un papel fundamental, reconstruyendo el pasado reciente del Paraguay y sus primeros gobernantes. Bajo el movimiento que Raúl Amaral Ilamó "regeneración" (2003: p. 29)², se presentó a la Triple Alianza como el ejército liberador de un pueblo sometido a las voluntades de sus "tiranos" - en especial la del último de ellos: Francisco Solano López -, quienes habían sumido al país en la "barbarie". La guerra fue la empresa necesaria para luchar contra el "tirano" López, y llevar la "civilización" al Paraguay para el bien de su pueblo.

Sin embargo, lejos de la estabilidad política, social y económica que proponían los liberales triunfantes, en palabras de Efraím Cardozo, «La vida política fue una sucesión de golpes de Estado y revoluciones» (2009: p. 113). La reconstrucción paraguaya estaba costando mucho más de lo que se había pensado, teniendo temas irresueltos que pulsaban por debajo de cada nuevo gobierno. La Historia no era ajena a esto, así el discurso liberal chocaba con la memoria de los sobrevivientes de ese pasado enjuiciado. Como señala Luc Capdevila (2010), los distintos recuerdos y percepciones del Paraguay previo a la Guerra de la Triple Alianza, y del propio conflicto, se encontraban influenciados por las participaciones e intereses de cada individuo

2 Para este tema ver (Sansón, 2015; 2017a). 
y familia, así como la tradición que esta última transmitió a las generaciones venideras. De esta manera, lejos de existir un discurso homogéneo, voces disidentes comenzaron a hacerse oír; especialmente entre algunos de los integrantes del grupo de intelectuales que constituirían la primera élite cultural paraguaya de posguerra, los denominados "novecentistas". Será la actuación de esta élite, y su expresión cultural, intelectual e ideológica en torno al Instituto Paraguayo, particularmente en la Revista de dicha institución, el objeto de estudio de este trabajo.

Como tema central, se indagará sobre las "representaciones del pasado" que pueden hallarse a lo largo de los sesenta y cuatro números de la Revista del Instituto Paraguayo. Esta categoría es señalada por Paul Ricoeur en su libro La Memoria, la Historia, el Olvido (2004). El autor explica que la operación historiográfica consiste en tres fases. La primera, refiere al trabajo heurístico con el relevamiento y selección de documentación. Una segunda que refiere a la explicación y comprensión del pasado, a partir de los testimonios del pasado.
$Y$, finalmente, la narración de la representación que se construye sobre el pasado. En esta última se introduce la representación historiadora al momento de la escrituración. Desde su perspectiva, toda historia es escrita, desde su primera fase hasta la última. No obstante, es en la tercera cuando el trabajo del historiador toma forma de representación del pasado en su materialidad escriturada.

Ricoeur señala que el término "representación" se justifica de varias formas. En primer lugar, permite mantener una continuidad entre la fase heurística y selección documental, la fase explicativa-comprensiva, y la fase escrituraria. En segundo lugar, la representación se relaciona con la interpretación, señalando el vínculo entre la memoria, los nexos entre esta y los agentes sociales, y la investigación histórica. Finalmente, señala que la representación del pasado no es solamente una construcción narrativa, sino que se constituye como objeto intencional que «[...] hace de la historia la heredera erudita de la memoria y de su aporía fundadora» (2004: p. 309). El carácter inten- 
cional se manifiesta, explícita o implícitamente, a lo largo de las tres fases. En este sentido, la representación del pasado es el resultado final de la operación historiográfica, una vez que esta obtiene su materialidad discursiva - por lo tanto, cargada de intención y sentido - al momento de su escrituración.

Fabio Wasserman retoma este concepto indicado por Ricoeur, para hacer referencia a distintos ensayos o textos de diversos géneros que, con mayor o menor erudición, reflexionan y escriben sobre el pasado «[...] en un marco sociopolítico común con el fin de legitimar distintas posiciones e intereses» (2008: p. 35). En este sentido, extrapolándolo al caso de la Revista, refiere a los distintos artículos de diversos tipos, enfoques y estilos que opinan, analizan o comentan temas del pasado paraguayo, en un ambiente intelectual ávido de revisitar la historia nacional. Sin embargo, para el presente análisis, se dejarán de lado distintos textos literarios - principalmente poemas -, por entender que los mismos requieren un estudio particular, distinto al enfoque de este trabajo.

Bajo un análisis cualitativo, y cuantitativo, se apelará a encontrar cual es la época del pasado paraguayo que más abordan los artículos relevados, así como la metodología detrás de ellos.

\section{El Novecentismo paraguayo.}

Tras la victoria aliada, la condena al Mariscal, y los gobiernos anteriores, se estableció como interpretación oficial y legitimadora del nuevo gobierno paraguayo. El discurso aliado, y de los exiliados que retornaban al país, señaló que el Paraguay estaba sumido en el atraso debido a los gobiernos tiránicos de Francia y los López; la Triple Alianza trajo la civilización y la libertad, para erradicar la barbarie en que se encontraba el pueblo paraguayo (Sansón, 2015; 2017)³. A partir

3 La historiografía paraguaya se caracterizó por el peso de la "mediterraneidad". Como lo destaca Liliana M. Brezzo, la historiografía en el Paraguay atravesó un aislamiento debido a las circunstancias históricas, políticas, culturales, económicas y sociales particulares: su carácter de zona periférica del imperio español; el rápido mestizaje y las esca- 
de la Constitución de 1870, el Paraguay se encaminaría en una "regeneración" necesaria para garantizar la civilización y la paz en su territorio.

Sin embargo, la corrupción, la crisis económica, la desigualdad y la inestabilidad política truncaron el proyecto liberal. De esta manera, esta interpretación del pasado paraguayo comenzó a ser criticada hacia fines del siglo XIX y principios del XX: Ia Triple Alianza no logró hacer realidad lo que pregonaba; era necesario dar otra explicación al presente, otra legitimación para una reconstrucción distinta. Explica Brezzo que, en ese escenario, las interrogantes de «[...] qué fue, qué era y qué debía ser el Paraguay, es lo que movió a indagar los hechos del pasado reciente. Es en ese contexto cuando hizo eclosión el oficio del historiador y se produjo el primer discurso histórico sobre la Revolución del 14 de Mayo de 1811, los gobiernos de la primera mitad del siglo XIX y sobre el reciente cataclismo bélico» (2009: p. 64).

Un grupo de jóvenes, formados en el Colegio Nacional de Asunción y en la Facultad de Derecho de la Universidad Nacional, fueron quienes Ilevaron a cabo este movimiento crítico, adquiriendo un rol fundamental en la cultura paraguaya. Mejor conocidos como la "Generación del 900" o los "Novecentistas", iniciaron un proyecto cultural y político en un contexto de penuria posbélico.

El "Novecentismo" fue señalado por primera vez por Cardús Huerta hacia 1922, delimitando su periodo cronológico. Sin embargo, el nombre fue acuñado por Juan E. O'Leary en 1950 (Amaral, 2006: p. 81). Raúl Amaral señala que se

sas migraciones importantes la península, dando «[...] lugar a una rápida suplantación del grupo conquistador blanco por el grupo mestizo y criollo [...]» (2010a: p. 17); el dominio de la lengua guaraní en la vida cotidiana; y la ausencia de una universidad y una imprenta propia, menguando «[...] las posibilidades de una formación de élites intelectuales y la circulación de libros e impresos» (Ibid: ibid.). Sumado al amurallamiento político de Gaspar Rodríguez de Francia, el Paraguay se constituyó como un territorio desconocido. De esta manera, durante el período decimonónico las numerosas obras sobre la historia y la geografía del país fueron realizadas por viajeros, diplomáticos y escritores extranjeros (Brezzo, 2009: p. 62). 
entiende por "novecentismo" a una renovación de los modos de vida, la orientación intelectual y la comprensión histórica del pasado paraguayo - en especial ante el recuerdo y la percepción de la Guerra de la Triple Alianza, luego de treinta años de ocurrida - (Ibíd.: p. 57). Así, los integrantes de esta generación:

\section{"[...] buscaron explica- ción a los males patrios - aumentados o mini- mizados de acuerdo a la óptica personal -, procurando retomar la quebrada orientación del pasado, como una forma de rehacer las antiguas bases de la nacionali- dad, dramáticamente removidas por la Guerra contra la Triple Alianza y sus consecuencias, en particular político-so- ciales [...]» (Ibíd.: p. 35).}

Dentro de este movimiento pueden ser ubicados los nacidos entre 1870 y 1880 - con las excepciones de Cecilio Báez (1862-1941), Arsenio López Decoud (1867-1945), y Manuel Domínguez (1868-1935) -, teniendo como principales exponentes a: Manuel Gondra
(1871-1927), Teodosio González (1871-1932), Fulgencio R. Moreno (1872-1933), Blas Garay (1873-1899), Juan Francisco Pérez Acosta (1873-1968), Eusebio Ayala (1875-1942), Silvano Mosqueira (1875-1954), Ramón I. Cardozo (1876-1943), Gualberto Cardús Huerta (18781949), Eligio Ayala (1878-1930), Juan E. O'Leary (1879-1969), Juan León Mallorquín (1880-1947), Ricardo Brugada (hijo, 1880 1920), Ignacio A. Pane (18801920), J. Inocencio Lezcano (1880-1935), y Juan José Soler (1880-1963) (Ibíd.: pp. 19-20).

Descriptos como una "rebelión juvenil" (Ibíd.: p. 31), puede señalarse el punto de partida de su actuación en las publicaciones y la posterior muerte de Blas Garay (18 de diciembre de 1899), y su culminación con el fallecimiento de Eligio Ayala (24 de octubre de 1930). Desde su comienzo, la Historia ocupó un papel fundamental en las actividades de los "Novecentistas". Este nuevo discurso, gestado en este movimiento, progresivamente desplazó la historiografía aliada, estructurando una interpretación pasado que apeló revisar la "cuestión nacional" del Paraguay - enten- 
dida esta como la preocupación por el presente nacional, el pasado y los proyectos para su regeneración/reconstrucción -.

A grandes rasgos, la historiografía novecentista reivindicaba la particularidad del Paraguay como un país sui generis, cuyas características naturales, culturales y políticas lograron establecerlo como un Estado original para la región rioplatense. Los gobiernos de Francia y de los López habían generado estabilidad y desarrollo superior a sus vecinos, a pesar de las críticas y objeciones sobre las características de sus regímenes. Sin embargo, la Guerra de la Triple Alianza vino a truncar ese desarrollo, llevando al pueblo paraguayo a una situación de penuria que aún hoy persiste.

Esa experiencia de guerra que unía a todos los paraguayos, incluidos estos intelectuales, generaron diversas relaciones con el pasado. Pero fue esta generación la que se embanderó con la tarea de "revisar" el discurso histórico, haciendo de la labor histórica la base para comprender y cambiar la penuria de su presente. Sus actividades, lejos de ser solitarias, se enmarcaban en un movimiento que vio su integración, junto a otros intelectuales y generaciones, en la fundación del Instituto Paraguayo hacia $1895^{4}$. Rafael Eladio Vázquez explica que la conformación de esta institución por parte de trece jóvenes intelectuales se convirtió en «[...] la entidad cultural de mayor trascendencia de su tiempo. Antes de cumplirse un año, más de un centenar de nuevos socios se sumaría al grupo fundador. Esta corporación nucleó pronto a todo el mundo intelectual de entonces [...]» (1999: pp. 206207). En palabras de Brezzo:

«En un comienzo sus impulsores se limitaron a enunciar entre sus propósitos el fomento del estudio de la música y el desarrollo de la literatura, proporcionar la enseñanza de idiomas y

$4 \quad$ Es menester señalar que, en los meses posteriores a la fundación del Instituto Paraguayo, se conformó el Instituto Histórico del Paraguay. Bárbara Gómez (Junio 2019) analiza la efímera existencia de esta institución, la cual fue concebida como complementaria al Instituto Paraguayo. 
estimular los ejercicios físicos por medio de la gimnasia y la esgrima. Sin embargo, las cuestiones sobre el pasado se constituyeron, al poco tiempo, en materia predominante de las conferencias, de los discursos y de otras actividades llevadas a cabo por la institución, las que, en todos los casos, suponían un punto de referencia, un indicador preciso de los rumbos temáticos consagrados por esa élite intelectual; se impuso entonces la necesidad de divulgar tales emprendimientos a través de una Revista» (2010: pp. 212-213).

De esta manera, hacia 1896 surge el primero de sesenta y cuatro números de la Revista del Instituto Paraguayo. La misma sería definida como publicación cuyo carácter era esencialmente científico; será al poco tiempo que se daría prioridad a la labor histórica, subtitulándose luego como "Historia, Ciencias, Letras" (Ibíd.: p. 213).

Los "Novecentistas" fueron construyendo un relato nacio- nalista a través de corrientes de pensamiento dispares y de diversas manifestaciones culturales (Amaral, 2006; 2010). Ante un territorio devastado en todos los sentidos, estos intelectuales estaban lejos de abstraerse de su realidad. Por el contrario, se vieron comprometidos a interpretar lo que los rodeaba, encontrando en la prosa el instrumento necesario. La formación literaria del novecentismo permitió acoplar las diversas influencias europeas y americanas, introduciendo y absorbiendo «[...] métodos, sistemas, procedimientos, en muchos casos de épocas diferentes; fundirlos en la mentalidad nativa y dar sitio a una expresión de cultura propia» (Amaral, 2006: p. 67). Con la adaptación de corrientes ideológicas diversas al medio paraguayo, y con una narración épica al momento de la escritura de la Historia, el "Novecentismo" constituyó una identidad propia. Se conformó como una generación dispuesta a renovar las bases ideológicas e históricas de un Paraguay en ruinas.

La importancia del pasado para esta generación se enmarca en un contexto de avidez por 
revisitarlo 5 . Como lo destaca dad paraguaya; en especial Josefina Plá, la Historia fue la el complejo pasado reciente, principal manifestación cultural para responder a cuestiones irresueltas para la socieante una memoria posbélica que no encontraba lugar en la historiografía anterior. De esta

$5 \quad$ La importancia del pasado puede observarse en las repercusiones de la polémica en la prensa entre Cecilio Baéz y Juan O'Leary iniciada en 1902. Repercusiones no solo en las argumentaciones dadas en los periódicos, sino también en los apoyos institucionales, políticos y sociales manifestados. Liliana Brezzo (2012), en el estudio preliminar a la compilación de dicha polémica, repasa la biografía de ambos intelectuales, su formación en la materia, su vinculación entre sí y con el Instituto Paraguayo, así como los principales postulados de ambas posiciones. A lo largo del intercambio entre ambos intelectuales es posible observar la conformación de dos discursos que dividieron tanto la intelectualidad, así como la sociedad paraguaya. Por un lado, Cecilio Báez plantea que los gobiernos tiránicos de Francia y los López eran los responsables de la situación penosa del Paraguay, al no haber dado la principal herramienta para el desarrollo de la nación: la educación. Resaltando que el heroísmo del soldado paraguayo no estaba puesto en duda, entiende que la Guerra de la Triple Alianza llevó aún más a la ruina al país debido al capricho del tirano Solano López. Por otro lado, Juan O'Leary, bajo el seudónimo de Pompeyo Gonzales, se colocó en las antípodas de la postura de Báez, discutiéndole punto por punto la postura de éste. Repasando desde el período colonial hasta la guerra, va mostrando como el pueblo paraguayo se constituía como una sociedad original, distinta a cualquier otra por sus características únicas. Encontró en Gaspar Rodríguez de Francia el fundador de la Nación y el Estado independiente del Paraguay, dando inicio a la edad dorada de este. Exalta las medidas de modernización bajo el gobierno de Carlos Antonio López, colocándolo como el punto más álgido de este proceso. Al momento de referirse a Solano López, este no se ocupa de reivindicarlo - algo que si hará a la postre -, sino que incluso lo llama verdugo del pueblo paraguayo. Sin embargo, entiende que la causa por la que lucharon contra la Triple Alianza es legítima, y exalta el valor de los soldados como defensores de una patria sin igual en el Rio de la Plata, y que los aliados vinieron a destruir. La autora prosigue el trabajo estudiando las repercusiones de esta polémica, considerándola fundante para la historiografía nacionalista que logra imponerse, con la figura de O'Leary como su escriba. Este trabajo es fundamental para entender el contexto en que se ubica este trabajo: un período de gran preocupación general por un pasado reciente que no había encontrado espacios para la expresión de una memoria latente. Un contexto donde la Historia se estableció como la principal disciplina social estructurante de la cultura, la identidad y la Nación del estado guaraní. 
manera, otras manifestaciones culturales se vieron desplazadas ante el discurso histórico por considerarse «[...] inoperantes en la tarea que especialmente les preocupó: la definición de una conciencia histórica, la educación en un sistema de valores universales que prestase sentido a un devenir. Era a todas luces urgente dar a este pueblo abrumado, desnor- teado [sic] una fe, un ideario, un rumbo» (Brezzo, 2009: p. 68).

En este marco, el "Novecentismo" y su actuación se convierte en una etapa fundamental en el desarrollo historiográfico del Paraguay. Su actuación y su legado aún permanecen vigentes en el pensamiento histórico cotidiano.

\section{La Revista del Instituto Paraguayo.}

Ante lo dicho en los pará- historiográfico que avanzó grafos anteriores es plausible por carriles distintos de las pensar en la Revista del Instituto Paraguayo como una fuente importante para comprender la formación y difusión del pensamiento novecentista, y, por ende, el desarrollo de la labor histórica en el país. A través de esta, es posible conocer los lineamientos de la mencionada generación, resultando clave para comprender un campo demás historiografías del Río de la Plata (Sansón, 2015; 2017).

Como se mencionó anteriormente, surgida hacia 1896, con un total de sesenta y cuatro números, la Revista puede ser pensada como espacio de formación, intercambio, nucleamiento y difusión de la historiografía novecentista ${ }^{6}$. Es necesario

$6 \quad$ Es necesario señalar que existe una interesante cantidad de artículos que se dedican a la difusión de catálogos e índices, así como otros que señalan las publicaciones más importantes y su correspondiente crítica. Por otro lado, hacia el final de muchos números, figura una sección de "Canje", donde se da cuenta de las distintas publicaciones periódicas, de diversos países, que el Instituto está dispuesto a intercambiar o adquirir. Si bien esto requiere un análisis más profundo, las páginas dedicadas a la difusión de índices y catálogos, crítica de publicaciones, e intercambio hemerográfico, sumado a las promociones suscripción - para nacionales y extranjeros - que se promocionan en la Revista, marcan una intención de difundir esta publicación en el territorio para- 
señalar que esta publicación no fue únicamente expresión de esta generación; la diversidad de autores da cuenta de que muchos extranjeros y nacionales, ajenos a los marcos cronológicos del novecentismo, participan en los distintos números. No obstante, si puede ser entendido como un espacio importante donde los novecentistas pudieron desarrollar sus actividades intelectuales.

La Revista se publicó ininterrumpidamente hasta 1909, y su principal contenido gira en torno a la Historia, la literatura, el teatro y otras actividades culturales. Como se señaló con anterioridad, la Historia comenzó a tener un peso mayor en la temática de dicha publicación a medida que avanzan los números. Desde un inicio es posible observar la importancia que el pasado ocupa en esta publicación. En el primer número se expresan los objetivos de la Revista, la cual apela al «[...] desarrollo de la cultura intelectual y artística y del espíritu de asociación, tan útiles al humano progreso» (1896: p. 1). Esta se define de «[...] carácter esencialmente científico, literario e histórico», siendo dicha publicación un «verdadero acontecimiento [...] para nuestra querida patria, única quizás en el mundo civilizado desposeída de una publicación de este género» (Ibid: ibíd.). Augurando la importancia de esta revista, la publicación de Instituto Paraguayo se coloca como un hito en el desarrollo cultural del Paraguay, ya que se ocupará de dar cuenta de «[...] la ilíada y la odisea de su interesantísima historia, sublime epopeya en que no se sabe qué admirar más, si la nobleza y el valor insuperable de este pueblo mártir o la tenacidad de su infortunio» (Ibid: pp. 1-2).

Como se puede observar, la tarea de recuperar un pasado grandioso es explicitado en dicha cita, otorgándole a esta publicación y a sus autores una "misión patriótica": el Paraguay necesita «[...] cultores e intérpretes que reivindiquen en pró de nuestra amada patria, el asiento que legítimamente le corresponde en el banquete intelectual á que le brindan sus ilustres hermanas de la América latina, y del que permanece alejada, por no poder presentarse con los atavíos que 
su dignidad le impusiera» (Ibid: puede ser visto con mayor clap. 2). Tal vez, este sentido misio- ridad en el siguiente pasaje: nal que se adjudica la Revista,

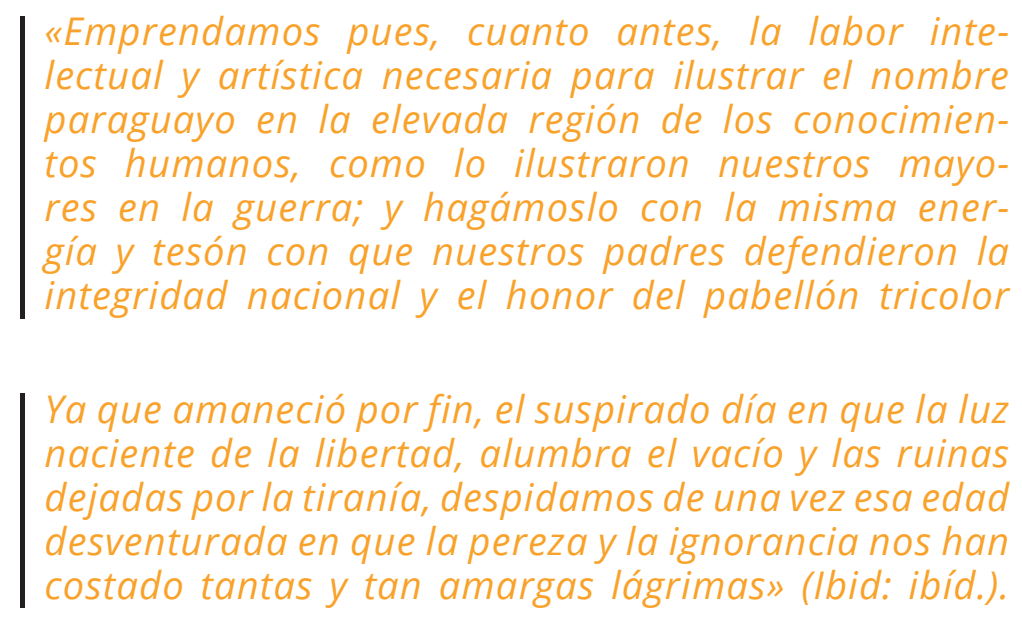

En esta posición de representantes de un movimiento que busca reconstruir la cultura del Paraguay - en especial la recuperación de un pasado glorioso -, la Revista se dirige a la nueva generación de paraguayos. Esta, «[...] Ilena de aspiraciones, de bríos y provista de una preparación muy superior a la anterior, no puede ni debe permanecer en la ociosidad intelectual y abandono del arte» (Ibid: ibíd.).

De esta manera, el Ilamado hecho por dicha publicación apela a esta generación cuyo deber será darle un impulso cultural al país para hacerle justicia a su historia.
Deberán, por lo tanto, poner todos sus esfuerzos «[...] con la elevación y cultura con que debemos tratarnos en sociedad y en un escrupuloso respeto por la verdad histórica» (Ibid: p. 3). La Revista se presenta así, desde su primer número, como el medio necesario para que esta generación cumpla con el deber recae sobre estos: la "reconstrucción cultural del Paraguay", haciéndole "justicia” a su historia.

En resumen, esta breve descripción de la fuente permite pensar a la Revista del Instituto Paraguayo como el espacio de formación y divulgación de la “Generación del 900". Sus pági- 
nas fueron una herramienta con la cual darán una nueva lectura al pasado. En otras palabras, una fuente importante para comprender la conformación del Novecentismo, y su accionar.

\section{Representar el pasado.}

Como se ha observado, la Revista del Instituto Paraguayo fue una de las publicaciones culturales más importante de entre siglos. En la misma, la Historia fue adquiriendo cada vez más importancia a medida que avanzan sus números - al igual que en la vida cultural paraguaya -. El análisis de esta publicación resulta relevante para comprender el desarrollo del espacio historiográfico del Paraguay.

En este sentido, el presente trabajo estudiará las "representaciones del pasado" (Ricoeur, 2004) (Wasserman, 2008) que pueden hallarse en esta publicación. Se han relevado 109 artículos, a lo largo de los sesenta y cuatro números, que hacen referencia a una reflexión histórica - tanto del pasado paraguayo, como de historia universal y/o de América -, desde un punto de vista más historiográfico, así como desde visiones filosóficas, económicas y políticas. Prestando atención a sus autores, es menester señalar que en su mayoría son paraguayos que pueden ser ubicados dentro del novecentismo, ya sea por su marco temporal - Belisario Rivarola, Blas Garay, Carlos L. Isasi, Fulgencio Moreno, Ignacio A. Pane, Juan E. Oleary, Juan J. Soler, Juan León Mallorquín y Teodosio González -, o por su papel como referente intelectual de esta generación. - Alejandro Audibert, Cecilio Báez, José Segundo Decoud y Manuel Domínguez -. A su vez, se relevaron artículos de algunos extranjeros que podrían ser ubicados dentro del pensamiento novecentista por su cercanía con este grupo gracias a sus actividades intelectuales, 0 incluso por residir en el propio territorio paraguayo. Ejemplo de esto son Guido Boggiani, Martín Goycochea Menéndez, Ramón Zubirratea y Viriato Díaz Pérez.

Como se mencionó anteriormente, este trabajo estudiará qué período del pasado paraguayo analizan las representaciones del pasado en la Revista del Instituto Paraguayo, así como la metodología detrás de estas. 
Comenzando por estudio del período del pasado paraguayo que más se aborda, se discriminaron los artículos en seis categorías: 1) Conquista y época Colonial; 2) Independencia y gobierno de Gaspar Rodríguez de Francia; 3) Gobierno de Carlos Antonio López; 4) Gobierno de Francisco Solano López y Guerra de la Triple Alianza; 5) Postguerra; y 6) Otros. Es menester dar cuenta que en la categoría de "Otros" se engloban temas de historia universal, así como ensayos de tipo filosóficos, etnográficos, lingüísticos, económico, entre otros, que en su mayoría están relacionados con el Paraguay - ya sea con su pasado, o con problemas del presente -. Otra aclaración pertinente es que estas categorías no son excluyentes, ya que varias de estas "representaciones del pasado" pueden abarcar distintas épocas del pasado paraguayo.

Dicho esto, puede constatarse que el $41,28 \%$ de los artículos refieren a la conquista - la época colonial. Luego lo sigue el período que abarca la Independencia y el gobierno de Rodríguez de Francia - con un 18,35\% -, y el Gobierno de Francisco Solano López y la
Guerra de la Triple Alianza con un $17,43 \%$-. Solamente un 11,01\% hacen referencia al período gobierno de Carlos Antonio López, y un 10,09\% a la Postguerra. Finalmente, un $42,2 \%$ puede ubicarse en la categoría de Otros, siendo esta cifra la más alta debido a la diversidad de temas y puntos de análisis que abarcan.

Es interesante señalar que existen temáticas comunes a pesar de la diferencia de períodos que tratan estas "representaciones del pasado", como por ejemplo la administración política del territorio paraguayo, sus límites, leyes de extranjería, y reflexiones en torno a la identidad nacional. No obstante, para cada época hay artículos que se focalizan en los gobernantes de turno; de eta manera, en períodos posterior a la independencia, surgen temáticas más específicas para cada uno de los presidentes paraguayos. De esta manera, los artículos correspondientes al período del gobierno del Dr. Francia se constatan artículos que estudian el carácter dictatorial de su mandato. Para el período de Carlos Antonio López, se pueden encontrar artículos 
sobre la navegación de los ríos y cuestiones monetarias. En el caso del período de gobierno de Francisco Solano López, y la Guerra de la Triple Alianza, también se tratan cuestiones monetarias, pero se agregan por obvias razones - artículos sobre la organización del ejército, batallas y represiones dentro del contexto bélico. Finalmente, para el período de Postguerra, también se tratan temas monetarios, y se puede hallar un énfasis mayor en temáticas sobre los límites de territorio paraguayo.

Volviendo a las cifras obtenidas según el período que abordan, se observa la preocupación mayoritaria sobre el período de conquista y el dominio colonial. Esta preocupación no es azarosa, pues el estudio de esta época se relaciona con el contexto expuesto: el objetivo de reconstrucción del Paraguay como Estado Nación. El estudio del período colonial permite conocer los límites originales del país - en especial en las tensas negociaciones con Bolivia, en torno al territorio del Chaco Boreal -, así como los orígenes de la "Nación paraguaya".

Este punto queda explicitado en la transcripción de la Conferencia del Dr. Alejandro Audibert, bajo el título «Límites con Bolivia» (1901). En la misma se aclara que esta viene a ser el "prólogo" de distintas conferencias que serán dadas en el Instituto Paraguayo. Y previo a dar paso a la palabra del conferencista, se expresa:

\section{"Las conferencias serán la demostración clara e irrefutable de la legitimidad de los derechos del Paraguay sobre el chaco boreal, derechos y títulos que Bolivia quiere desconocer, seguramente por- que no conoce los antecedentes históricos que legi- timan los derechos del Paraguay» (1901: p. 137).}

Este aspecto se refuerza en la carta de Cecilio Báez y Juan Cristónomo Centurión al Ministro de Relaciones Exteriores, José Segundo Decoud, el 31 de Marzo de 1898. La misma es transcripta por la Revista como nota preliminar a la reproducción de los capítulos del «Informe encomendado por el Congreso 
de la Nación para el estudio del mentan la posición paraguaya tratado Benítez-Ichazo». Bajo en el uti-possidetis del territoidéntico título que la conferencia rio del Chaco, añadiendo que: de Audibert, los autores funda-
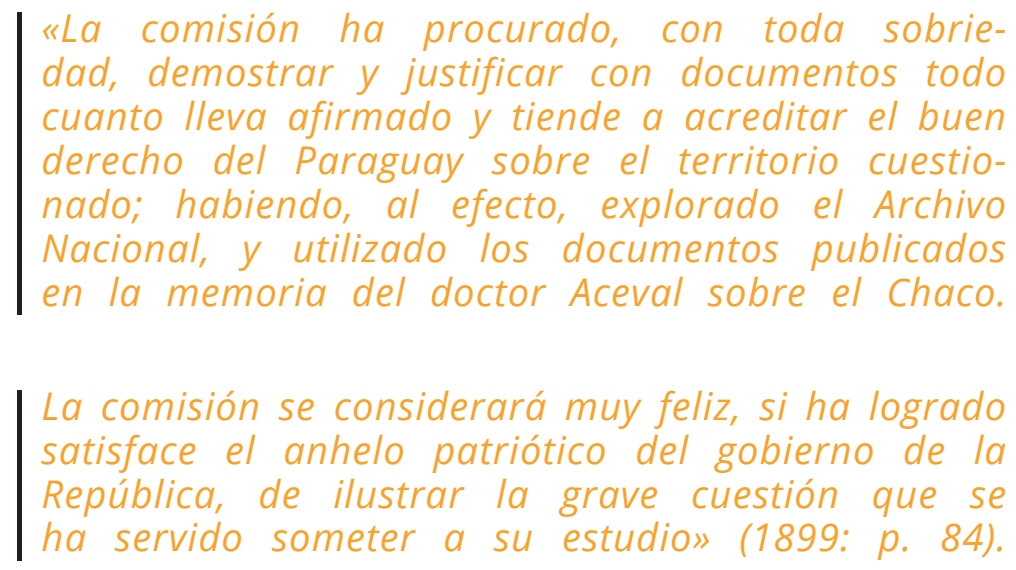

Por otro lado, el estudio de ese heroísmo y arrojo con de la época colonial no solo que se caracterizaba al pueblo indagó en las cuestiones de paraguayo. Así, expresa que su límites, sino que se aventuró en trabajo «[...] será, en parte y de perspectivas de "psicohistoria". paso, un modestísimo ensayo Bajo esta postura define Manuel de psicología histórica, en Domínguez el artículo que figura que hubiera sido mejor que en el $N^{\circ} 38$, con el título «Cau- se ejercitase la inteligencia de sas del heroísmo paraguayo» un Taine, la penetración fina (1903). Este es una transcripción de un Renan» (Ibíd.: p. 645)7. de la conferencia que el autor Bajo esta perspectiva, el autor dio en el Instituto Paraguayo procede a rastrear los distintos el 29 de enero de 1903. En la factores que fueron compomisma, Domínguez explicita niendo el "heroísmo paraguayo", que quiere buscar los orígenes viendo en la época colonial el

7 La cita de estos autores no es un hecho aislado. En distintos artículos a lo largo de la Revista del Instituto Paraguayo se pueden encontrar referencias a estos intelectuales y otros, dando cuenta una circulación de textos, ideas, conocimientos y conceptos, que merecerían un estudio particular. 
período de gestación de una "raza sui generis": el hombre paraguayo. Un hombre que lo considera superior, debido a un mestizaje privilegiado que recoge lo mejor de la raza blanca europea, y lo mejor del elemento indígena guaraní -, una geografía privilegiada, una superioridad física, y un modo de vida que delimita un carácter aguerrido pero pacífico, astuto e inteligente. Expresa que esto se vio potenciado con la vida Independiente, solidificando una unidad comunitaria ya existente, haciendo que - en referencia a los países vecinos, particularmente aquellos que integraron la Triple Alianza -:

«El Paraguay [fu]era superior a cada aliado como Nación. No era como la República Argentina, una amalgama heterogénea de porteños y provincianos, federales y unitarios que se odiaban a muerte; no estaba como el Brasil fraccionado en republicanos e imperialistas, en señores y millones de esclavos. El Paraguay era una unidad política, quizás la más compacta y homogénea que vio jamás, con una sola voluntad, con un solo sentimiento: en el peligro común se levantaría como un solo hombre.

\section{Y aquellas energías debi- das a las particularida- des de su geografía y de su historia representa- ban un capital guerrero enorme» (Ibíd.: p. 672).}

Así, el estudio del pasado, y en particular el estudio del período colonial apeló a buscar estos rasgos originales de la nacionalidad paraguaya. $\mathrm{O}$, mejor dicho, rastrear la "grandeza de la patria" con el fin de transmitirlo, como se expresa, a las generaciones venidera,

Esto se relaciona con la metodología ensayada por los distintos autores de "representaciones del pasado". En este sentido, puede rastrearse cómo la referenciación de fuentes y bibliografía es una constante a lo largo de los artículos relevados. De los 109 capítulos dentro de la categoría de "representaciones del pasado", el 93,58\% cita - con mayor o menor erudición - documentos o bibliografía sobre el tema que reflexionan. Una característica 
que resulta central si se tiene en cuenta la difusión de documentación histórica que la propia Revista realiza en sus distintos números: la necesidad de respaldar las representaciones del pasado en documentación histórica como forma de dar carácter de "cientificidad" a la tarea investigativa. Esto no es extraño si se tiene en cuenta el proceso de formación del espacio historiográfico de los países vecinos. Tanto Brasil como la región rioplatense tuvieron muy presente cómo debe ser reconstruido el pasado, esgrimiendo una metodología que era defendida y practicada en los distintos institutos - Instituto Histórico y Geográfico de Brasil, Instituto Histórico y Geográfico de Montevideo, Junta de Historia y Numismática Americana en Buenos Aires - (Sansón, 2015; 2017). En similar sintonía, el Instituto Paraguayo y su publicación continúa este modelo que varias décadas atrás sus vecinos habían comenzado. La influencia del temprano desarrollo de la historiografía brasilera en el siglo XIX, y su posterior influencia en el territorio rioplatense, no estuvo ajena al Paraguay. Luego de 1870 con el retorno de los emigrados paraguayos, sumado a la influencia aliada aún presente en el país, el modelo de desarrollo historiográfico comienza a gravitar fuertemente en el espacio historiográfico del Paraguay. Será con la Generación del 900 y con la conformación del Instituto que se avanzaría significativamente en proceso.

Los Novecentistas, como integrantes de una generación que busca contagiar a toda la sociedad, ven en esta "reconstrucción científica" de la historia del Paraguay la forma de "esculpir la Patria", como expresaba Juan Silvano Godoy en el N60: 


\section{I se comunique hable, se haga escuchar, comprender; y luego, se inponga [sic], conquiste respeto, conside- ración, personería jurídica mundial» (1908: p. 605).}

La cita anterior corresponde a su trabajo «La Patria» - el cual dedica «Al eminente uruguayo Dr. Luis Alberto de Herrera» (Ibíd.: p. 581) -. En este, Godoy da cuenta de cómo ha evolucionado el concepto de "Patria" y como este puede ser concebido, comparándolo con la realidad paraguaya. Sus expresiones resultan interesantes, pues son una muestra de cómo se concibe en el contexto de este análisis la construcción de la "Patria" o la nacionalidad. Este trabajo con el cincel, ese sacar a la luz la escultura atrapada en el mármol, permite inferir una interpretación de la Historia, y como esta interactúa con la conformación de la Nación. Citando el trabajo de Bárbara Gómez, «Verdad e Historia en la Revolución de la Independencia del Paraguay de Blas Garay», la autora comenta que la concepción que Blas Garay tenía de la historia coloca al historiador como el «[...] vehículo por el que se debían expresar las fuentes y contar cómo habían sucedido los hechos, en este sentido acallar las percepciones del historiador en tanto sujeto histórico para que las fuentes puedan hablar por si misa, era una acción fundamental» (2016: pp. 81-82). Señala Gómez, que Garay entiende que:

\section{"[...] "la historia atestigua" como si fuera una entidad autónoma. Esta es concebida y percibida con carác- ter independiente, el desarrollo histórico tiene diná- mica propia, tiene autonomía de sus protagonistas y de sus relatores, la historia se mueve sola y ella es en símisma. Esta concepción típica del pensamiento histórico europeo del siglo XIX, es lo que común- mente se identifica como una de las características de la historia moderna, concepción devenida de la filosofía de la historia hegeliana» (Ibíd.: pp. 75-76).}

Esta idea de una "Historia sola, independiente de la volunatestiguadora", que se mueve tad humana, puede ser rastreada 
en este contexto historiográfico la misma, se dice que, aunque paraguayo. En el $N^{\circ} 44$, como «A primera vista pareciera inofiprólogo a la publicación de ciosa la publicación en nuestra "Guerra del Paraguay. Memo- Revista de la memoria militar ria militar sobre el estado de del general Mitre, referente la Guerra con el Paraguay en 1867, y sobre los planes de campaña y operaciones á ejecutar, demostrando la probabilidad de forzar el Paso de Humaita", La Dirección publica una breve nota previa titulada «La memoria á la guerra del Paraguay [...]» (1903a: p. 68), esta posee documentos inéditos que resultan de utilidad para investigar la dilatación del conflicto con la Triple Alianza. Continuando con la nota, se aclara lo siguiente: militar del General Mitre». En

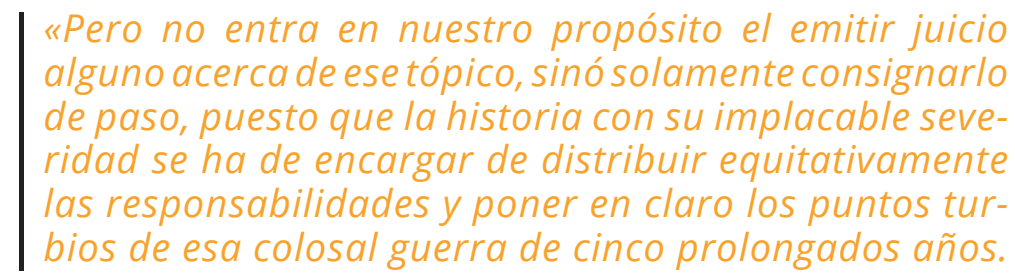

Siendo, de otro lado, nuestro especial afán concu-
rrir con materiales para escribirse la historia nacio-
nal, aún en blanco, ofrecemos, como en un haz,
esas correspondencias del generalísimo del Ejército
de la Triple Alianza, á los que se dedican con lau-
dable empeño á desentrañar el pasado con aquella
elevación de miras é independencia de criterio que
demanda la ciencia de verdad, muy ajena á los estalli-
dos de las pasiones extraviadas, la cual sin violación
no se ha de prestar á que á su amparo se denigre con
la soltura de lengua que caracteriza á los dilettanti
que se las echan de historiadoresı (Ibíd.: pp. 68-69).

Surge a las claras lo dicho juicios correspondientes. Sin anteriormente: la historia se pre- embargo, esta concepción senta como entidad autónoma, imperante en el contexto de cuyo "tribunal" dispensará los desarrollo historiográfico del 
novecentismo puso por encima de la "cientificidad" a las necesidades políticas, sociales y económicas. La recopilación, difusión, análisis y referenciación de la documentación histórica no parte de las fuentes para reconstruir la historia de la nación, sino que «[...] parte de una concepción de Estado-nación y desde ahí interpreta y lee las fuentes a partir de las cuales reconstruye la historia de la nación» (Gómez, 2016: p. 83).

La mencionada conferencia de Audibert, «Límites con Bolivia» (1901), ahonda aún más en esta posición. Su intervención comienza diciendo que la investigación requiere un sacrificio de recursos, tiempo y esfuerzo físico e intelectual, pero que vale la pena al ver a todos quienes acuden "al comercio de las ideas" para "[...] rectificar o ensanchar sus conocimientos» (Ibíd.: p. 139). Pero aún vale más ese esfuerzo al ver «[...] esa juventud ávida de curiosidad y de estudios, que se levanta entre escombros, sombras y ruinas del pasado, y los errores, preocupaciones e injusticias del presente, luchando con la pobreza y la miseria, a fin de consagrarse a las ciencias y a las letras» (Ibíd: ibíd.). Y exclama:

«Esa juventud forma la esperanza patria que reanima al espíritu, en el mismo lecho del desengaño; pero la virtud más poderosa que a todos nos reúne aquí, es seguramente una imagen que se aproxima a la divinidad: la Patria.

La patria! que no siendo de carne ni de hueso es incorruptible; que no teniendo figura, lleva por símbolos al escudo y la bandera; que no viviendo en reposo, siempre agita sus dolores e impele a sus hijos en pos del lenitivo de sus males, que ninguno de los cinco sentidos la atestigua, pero que existe» (Ibíd.: ibíd.).

Así, partiendo de esta "omnipresencia divina de la Patria", Audibert analiza los acontecimientos y documentos que justifican el derecho paraguayo sobre el Chaco Boreal, concluyendo que su trabajo no aspira a otra cosa que alcanzar la "verdad". Sus reflexiones 
finales resultan muy ilustrativas a los argumentos expuestos:

"La historia no tiene más amigos que la verdad, que podrá ser impolítica en el sentir de algunos; pero, a mi juicio, no hay mejor política que la práctica de ella. Yo no aspiro a ser patriotero, ni un discípulo de Maquiavelo

Mi deseo y satisfacción consisten en decir la verdad
y ajustar mis actos a ella, porque tengo la convic-
ción que redimirá al país de los errores de sus hijos
[...] Nada nuevo ofreceré que no esté contenido en
libros, publicaciones y documentos, pero es mi pro-
pósito contribuir a formar el armazón de la historia
nacional, tal cual es, fijando los límites dentro de los
cuales se realizaron los hechos, esfuerzos y sacrifi-
cios de nuestros mayores, en pró de la posteridad [...]

La integridad Nacional no es cosa de comercio, ni es materia de sentimentalismo: es cuestión de hecho y de derecho; esto es, cuestión de investigación y estudio.

La verdad concluirá por arreglar los límites
entre el Paraguay y Bolivia» (Ibíd.: pp. 166-167).

A partir de los distintos nación devastada por una guerra artículos analizados, y parafra- fratricida y las versiones que seando a Bárbara Gómez en expresanlas fuentes [...]» (2016: su análisis sobre las obras de p. 83). Así, sea la Patria, sea la Garay, puede apreciarse cómo Nación, esta se encuentra por la historiografía que practican encima de cualquier aspiración estos novecentistas se debate de "cientificidad". Se parte de en las contradicciones "[...] entre esta "omnipresencia" de la el bien mayor representado por los intereses del Estado-nación, cuestión nacional para representar el pasado; se propone y la necesidad de consolidar una reconstrucción donde el la identidad política de una método científico - la referen- 
ciación bibliográfica y crítica documental - está supeditado a las necesidades discursivas de construir un relato identitario, terapéutico y cohesionador.

Es menester tener en cuenta que esta difusión de "representaciones del pasado" se enmarcaba en un objetivo común a la intelectualidad paraguaya: la regeneración cultural. Esta era reclamada por la institución, y señalada como uno de sus principales metas. Tomando el ya mencionado postulado de Josefina Pla, es claro observar el papel que se le otorga a la Historia en este proceso. Desde el primer número esto se deja plasmado en los objetivos de esta publicación, el cual se apela sostener y cumplir durante toda la existencia de esta. Muestra de esto son las reflexiones realizadas en el $\mathrm{N}^{\circ} 43$, en el capítulo “Nuestra Misión" escrito por el Director de la Revista, Belisario Rivarola. El autor realiza una «[...] breve reseña de la utilidad que ofrece al país la Revista del Instituto Paraguayo» (1903: p. 371), en donde expresa que esta:

"Contribuye con suma y laudable eficacia á abrir paso al nombre manoseado y obscurecido de nuestra patria entre los pueblos más remotos que, á menudo, confunden lastimosamente al Paraguay con los Estados del Plata, haciéndolo una mera provincia de éstos, ó, mejor, de la República Argentina.

\section{Por ello, sobre los hijos de esta tierra pesa el sagrado deber de no descansar ni desmayar en la empresa de dar á conocer á nuestro país en el mundo civilizado con aquellas bondades que hacen de él una de las comarcas más habitables del globo» (Ibíd.: p. 372).}

Rivarola continúa diciendo que la Revista «[...] es anchurosa vía que conduce poco á poco á hacer efectivos esos patrióticos deseos, y sostenemos la verdad de nuestro aserto» (Ibíd.: p. 373). A pesar de que esta no se difunde como "debería" en el extranjero, los distintos números de esta «[...] van á parar en las corporaciones científicas y en manos de los obreros incansables del progreso que, en el tranquilo retiro 
del gabinete ó del laboratorio, de la civilización humana» extienden la ya larga cadena (Ibíd.: ibíd.). De esta manera:

"Esos amantes sinceros de la verdad, despojados de las añejas preocupaciones y resabios originados por rivalidades de razas ó de pueblos, rectifican las apreciaciones y juicios falsos divulgados por espíritus malevolentes y superficiales contra estos países poco conocidos y severamente juzgados» (Ibid: ibid).

En esta misión de "rege- necesita para cumplir con tan neración cultural", el Direc- anhelado objetivo en la siguiente tor de la Revista el autor deja extensa, pero necesaria, cita: claramente asentado que se

"Y hoy más que ayer, más que nunca, debemos recurrir al patriotismo no falsificado de todos los ciudadanos sinceros, para que nos pongamos á trabajar de consumo en la obra indispensable de cimentar en bases graníticas la nacionalidad paraguaya, encerrada dentro de un territorio reducido por los azares del destino á su última expresión geográfica.

Sin embargo, la verdadera grandeza de un pueblo no se debe medir por la extensión de su suelo, ni por el número de sus habitantes, sino por el carácter y la capacidad productora de éstos.

Lancemos, pues, con las miradas fijas en el porvenir á conquistar los venturosos dones que promete la civilización á los que la abrazan con sinceridad, constancia y fe inquebrantables.

Finalmente, nos complace en enviar por estas líneas un fraternal saludo á todos los órganos de publicidad, que, dentro y fuera del país, alimentan y persiguen los mismo ideales de ver la regeneración social 


\section{Iy política de la humanidad por el único camino que conduce á ella: La Ciencia» (Ibíd.: pp. 374-375).}

Sin embargo, estos "patrióticos" propósitos que el Instituto Paraguayo esgrime como su misión, se encuentra con obstáculos en el contexto paraguayo. El mismo Rivarola, hacia 1908, publica "La Revista. Su X año" en el $N^{\circ} 59$, dando cuenta de las dificultades para llevar a cabo esta regeneración cultural. Dice el autor que «Se ve palpable que el ambiente no es propicio á la elaboración del pensamiento y de las ideas; empero, ello no autoriza á renegar de la tarea de trabajar siempre en beneficio de la cultura patria» (1908: p. 470). A pesar de las dificultares, Rivarola destaca que los esfuerzos de la Revista por cumplir su objetivo se mantienen firmes:

"Esa indiferencia ó desdén no debe desanimar á los contados que se dedican á las investigacione[s] en busca de la verdad en los diversos ramos de la ciencia y del arte; pues no tardará en plantar definitivamente entre nosotros sus reales el reinado de la inteligencia.

Si ponemos en evidencia la peculiaridad de nues-
tro medio social bajo el aspecto de la producción
intelectual, es por hacer resaltar la improba labor
que se ha realizado para sostener una revista, que
más atrae la atención y la simpatía del extrangero,
que no la de los nacionales. Esto, regularmente,
derrochan todas sus energías en el surco no siem-
pre fecundo de una política ávida y devoradora. El Instituto, en medio de lo exígüo de sus recur-
sos nunca ha economizado esfuerzo, ni sacrifi-
cios para el sostenimiento de la Revista. En este
sentido tiene también su lote el gobierno, que le
pasa la mano. Y aún esperamos que le pasará más
generosa, más sin reserva» (Ibíd.: pp. 470-471). 
El artículo termina cooperación de todos los haciendo un llamado a la ciudadanos en esta tarea:

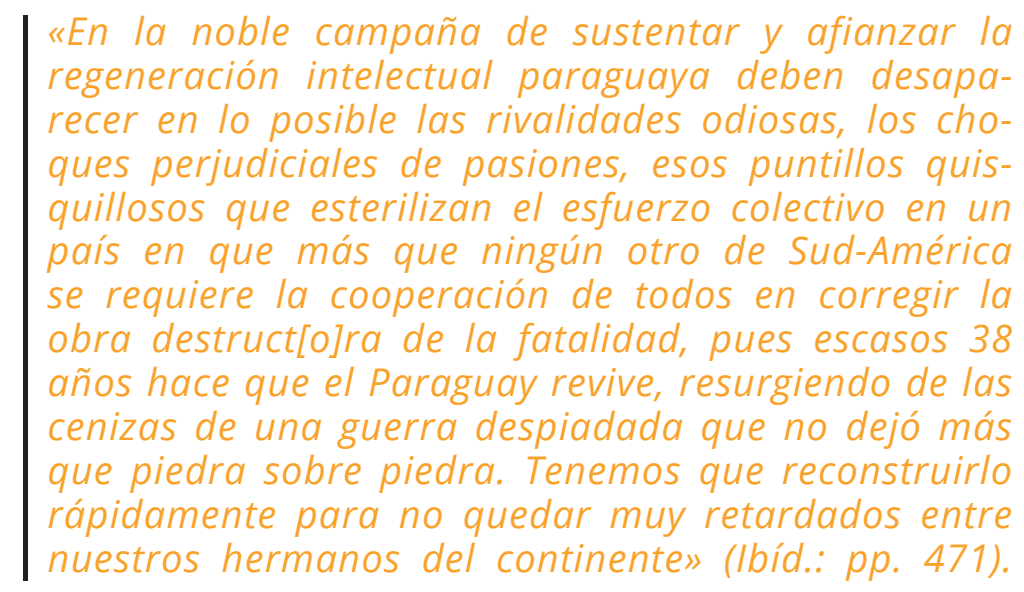

De esta manera, la Historia que se coloca como actividad esencial para la ansiada regeneración cultural. Así, realizar una Historia "científica" se colocaba como la principal vía para concretar los objetivos del Instituto, pues solo a través de esta se podría alcanzar la "verdad" y corregir los errores que "otras Historias" habían cometido.
En un contexto donde el Instituto trabaja y llama a colaborar con la "regeneración" cultural del Paraguay, la Historia es colocada como la principal manifestación para lograrlo. En el $N^{\circ} 53$, en el comentario que La Dirección hace sobre el documento ya publicado en el número anterior, "Informe del Gobernador del Paraguay, Agustín Fernando de Pinedo", se puede leer:

"Alguna vez se ha de pensar seriamente en reconocer la necesidad y conveniencia de tejer la Historia del Paraguay, y entonces se deslindará la responsabilidad que recaerá sobre esta generación que ha mirado y aun mira con marcado desdén todo cuanto atañe á nuestro pasado histórico. Quien no relaciona su conducta anterior con la posterior no cambiará con firmeza» (1906: p. 217). 
Esta necesidad de "tejer" la Historia del Paraguay se presenta como tarea fundamental para la construcción de la nacionalidad de dicho país. El llamado a la "esta generación" es un llamado a la sociedad paraguaya a comenzar a revisar el pasado y reconstruir un "nueva y verdadera" Historia; una Historia científica, que utilice las fuentes y bibliografía, criticándolas correctamente.

No obstante, esta concepción imperante en el contexto de desarrollo historiográfico del novecentismo puso por encima de la "cientificidad" a las necesidades políticas, sociales y económicas. Como señalaba Gómez, la recopilación, difusión y análisis de la documentación histórica no parte de las fuentes para reconstruir la historia de la nación, sino que parte de una concepción previa del Estado y de Nación, para luego leer las fuentes y reconstruir el pasado paraguayo (2016: p. 83). En este sentido, resulta interesante un artículo de un extranjero radicado en el Paraguay: Rafael Barret.

Barrett, periodista español que, habiendo llegado a Paraguay para cubrir la revolución liberal de 1904 como corresponsal del periódico El Tiempo de Argentina, entra en contactos con jóvenes intelectuales de dicho país. Termina asentándose finalmente en Asunción, participando en los distintos círculos de la intelectualidad paraguaya, y creando un grupo de tertulia literaria llamado "La Colmena". Su participación en la vida cultural paraguaya abarcó también su participación en la Revista del Instituto Paraguayo, particularmente en el $N^{\circ} 57$ en su artículo «En torno al libro del Doctor Báez» (1907). En este, Barrett reflexiona sobre el trabajo de Cecilio Báez, Cuadros históricos y descriptivos del Paraguay, señalando que es una agradable guía del pasado paraguayo, y sobre todo «[...] una labor de propaganda» (Ibíd.: p. 336). Las siguientes líneas resultan ilustrativas de lo anteriormente dicho: 


\section{I hubo, se contarán por los dedos. Hunde tantas raí- ces la política en nuestra sensibilidad filosófica, reli- giosa, social, que a la fuerza todo acto humano tiene un alcance político, por lo común inconsciente. Claro que no es este último caso de los Cuadros históricos. El autor no pertenece solamente a una cierta reli- gión, a una cierta escuela filosófica, a un cierto clan; pertenece además a un partido en que ha desempe- ñado importantes funciones, y cuyas tendencias ha dejado ver en la cátedra y ha desarrollado en lar- gas y robustas campañas periodísticas» (Ibíd.: ibíd.).}

Las palabras del escritor español resultan ilustrativas para estas reflexiones finales. Esta expresión de un contemporáneo a los novecentistas da cuenta de la percepción de la utilidad de la Historia: teniendo en cuenta que fue esta la principal manifestación cultural, es entendible que sea una herramienta predilecta para los objetivos políticos de las élites intelectuales. Así, Barrett entiende que toda Historia se encuentra influenciada por distintos aspectos de quien la escribe, en particular su posición e intereses políticos.
Los temas sobre el pasado paraguayo, y la forma de abordarlos, de las representaciones del pasado publicadas en la Revista pueden comprenderse bajo el esquema del intelectual español. La preocupación por la regeneración/reconstrucción cultural por parte de los Novecentistas se manifiesta en los artículos analizados, donde la representación del pasado se hace en búsqueda de explicaciones y respuestas para el presente; búsqueda que apeló a una metodología - con aspiraciones de cientificidad -, pero poniendo por delante los intereses en torno a la cuestión nacional. 


\section{Consideraciones finales.}

La diversidad de autores y temas que pueden hallarse en la Revista del Instituto Paraguayo tienen un hilo conductor: la necesidad del Paraguay de "regenerar su cultura" y construir su nacionalidad, a través de sus intelectuales.

En ese objetivo común de quienes participan en el Instituto, así como en su publicación, la Historia se presenta como una de las principales herramientas para alcanzarlo. Esta se coloca como manifestación cultural capaz de construir un discurso cohesionador e identitario, en un país que aún combatía viejos escollos de su reciente tragedia - la Guerra de la Triple Alianza - Abarcando distintos períodos del pasado paraguayo, fue la época colonial la más estudiada. Como se mencionó, esto no es azaroso, pues se encuentra estrechamente vinculado al contexto de producción. Las cuestiones de límites del país - especialmente con Bolivia -, así como la necesidad de establecer un relato identitario, hicieron de este período uno de los predilectos para encontrar los orígenes de la
Nación y sus "justos derechos" sobre territorios en disputa.

A lo largo del desarrollo de este trabajo, se procuró dar cuenta la importancia detrás de la publicación de "representaciones del pasado" en la Revista del Instituto Paraguayo. Teniendo en cuenta el carácter de la revista, la cual, si bien la historia era el área predominante de su temario, abarcaba otras manifestaciones culturales, resulta interesante la necesidad de difundir una manera de concebir y hacer Historia.

Sin embargo, este estudio del pasado no podía hacerse sin un método, pues devendrá en simple narración. La Historia debe ser practicada con un criterio científico, el cual la Revista buscó difundir: el uso de fuentes y bibliografía, con su correcto análisis a través de la crítica. Bajo esta perspectiva, las "representaciones del pasado" relevadas adquieren sentido dentro de la preocupación de estos novecentistas reunidos en el Instituto Paraguayo. Las páginas de esta publicación fungen como medio de difusión de las bases de un quehacer 
historiográfico en desarrollo. La una crítica rigurosa de estas, Generación del 900, a través de es posible alcanzar la "verdad" la Revista del Instituto, concibe de los hechos. No obstante, la una forma "correcta" de hacer cientificidad de la Historia se la Historia, y que fue ganando encuentra supeditada a los terreno poco a poco en el espa- intereses políticos, sociales, cio historiográfico paraguayo. culturales y económicos de estos novecentistas; intereses

A la par de una forma de tan diversos como la diversidad hacer Historia, se acompaña de artículos que se encuentran una concepción de la historia en la Revista, pero que tienen como existencia en sí misma. un hilo común: la regeneración La tarea del historiador es ser cultural, y la reconstrucción de su vehículo, y dar a conocer las una Historia "verdadera" del cosas tal cual sucedieron. Solo Paraguay escrita por paraguayos. a través de las fuentes, y de 


\section{Referencias bibliográficas}

Amaral, R. 2003. Escritos Paraguayos II. El magisterio de la libertad. <http://www.portalguarani.com/311_raul_amaral/1696_escritos_paraguayos_2_el_magisterio_de_la_libertad_2003_por_raul_amaral_html>, (Consultado el 11 de Julio de 2018).

Amaral, R. 2006. El Novecentismo paraguayo: hombres e ideas de una generación fundamental del Paraguay, Asunción, Servilibro.

Amaral, R. 2010. La filosofía en el Paraguay. Anticipos (1814-1918). Ensayos de Investigación cultural y bibliográfica, Asunción, Intercontinental Editora.

Brezzo, L. 2009. “El Paraguay en cinco momentos historiográficos: retos y perspectivas", en J. M. Casal, \& T. Whigham, Paraguay: nacionalismo y guerras, Asunción, Servilibro, pp. 61-78.

Brezzo, L. 2010. "«Reparar la Nación». Discursos históricos y responsabilidades nacionalistas en Paraguay", Historia Mexicana, Vol. LX, pp. 197-242.

Brezzo, L. 2010a. "La historia y los historiadores”, en I. Telesca, Historia del Paraguay, Asunción, Taurus, pp. 13-32.

Brezzo, L. 2012. “En el mundo de Ariadna y Penélope: Hilos, tejidos y urdimbre del nacimiento de la Historia en el Paraguay", en R. Scavone Yegros, \& S. Scavone Yegros, Polémica sobre la Historia del Paraguay, Asunción, Tiempo de Historia, pp. 13-65.

Capdevila, L. 2010. Una guerra total: Paraguay, 1864-1870. Ensayo de historia del tiempo presente, Buenos Aires, SB.

Cardozo, E. 2009. Breve historia del Paraguay. Asunción, Servilibro.

Gómez, B. 2016. “Verdad e Historia en la «Revolución de la Independencia del Paraguay» de Blas Garay", Estudios Paraguayos, Vol. XXXIV, N², pp. 65-85.

Gómez, B. 2019. "Instituto Histórico del Paraguay 1895-1896", Revista Paraguaya de Historia, V. II, N¹, pp. 125-151.

Ricoeur, P. 2004. La memoria, la historia, el olvido, Buenos Aires, Fondo de Cultura Económica.

Sansón, T. 2015. Despertar en Petrópolis, Andrés Lamas y la influencia de Brasil en la Historia de los Estados de la Cuenca del Plata en el siglo XIX, Montevideo, Sicut Serpentes.

Sansón, T. 2017. La nación y la pluma, Asunción, Tiempo de Historia.

Sansón, T. 2017a. "El campo historiográfico en Paraguay en la primera mitad del siglo XX: condicionamientos y monopolio interpretativo", Historio- 
grafía, $N^{\circ} 13$, pp. 53-73.

Velázquez, R.E. 1999. Breve Historia de la Cutlura en el Paraguay, Asunción, Centro de Publicaciones Universidad Católica Nuestra Señora de la Asunción.

Wasserman, F. 2008. Entre Clío y la Polís. Conocimiento histórico y representaciones del pasado en el Río de La Plata (1830-1860), Buenos Aires, Teseo.

\section{Fuentes referenciadas}

Audibert, A. 1901. "Límites con Bolivia”, Revista del Instituto Paraguayo, Vol. VII, N³2, pp. 137-167.

Báez, C. y Centurión, J.C. 1899. "Informe encomendado por el Congreso de la Nación para el estudio del tratado Benítez-Ichazo", Revista del Instituto Paraguayo, Vol. III, N¹6, pp. 81-105.

Barrett, R. 1907. "En torno al libro del Doctor Báez", Revista del Instituto Paraguayo, Vol. XII, N57, pp. 336-339.

Díaz Pérez, V. 1907. “Con motivo de unos documentos encontrados en el Archivo Histórico Nacional", Revista del Instituto Paraguayo, Vol. XII, N58, pp. 449-453.

Díaz Pérez, V. 1909. “Documentos de 1534 á 1600 que se conservan en el Archivo Nacional", Revista del Instituto Paraguayo, Vol. XIII, N 64, pp. 9851000.

Domínguez, M. 1902. "Prólogo", Revista del Instituto Paraguayo, Vol. VII, N 36, pp. 495-496.

Domínguez, M. 1903. "Causas del heroísmo paraguayo”, Revista del Instituto Paraguayo, Vol. VII, N³8, pp. 643-675.

Godoy, J.S. 1908. "La Patria”, Revista del Instituto Paraguayo, Vol. XII, N 60, pp. 581-609.

Instituto Paraguayo. 1896. "Nuestros propósitos”, Revista del Instituto Paraguayo, Vol. I., N¹, pp. 1-4.

Instituto Paraguayo. 1900. "Nota Preliminar", Revista del Instituto Paraguayo, Vol. VI, N²6, pp. 3-4.

Instituto Paraguayo. 1903. “Declaración de Guerra al Brasil y á la República Argentina", Revista del Instituto Paraguayo, V. VIII, N 40, pp. 30-49.

Instituto Paraguayo. 1903a. "La memoria militar del General Mitre", Revista del Instituto Paraguayo, Vol. IX, N44, pp. 68-69. 
Instituto Paraguayo. 1906. "Informe del Gobernador del Paraguay, Agustín Fernando de Pinedo", Revista del Instituto Paraguayo, Vol. XI, N 53, pp. 216-218.

Rivarola, B. 1903. “Nuestra Misión”, Revista del Instituto Paraguayo, Vol. VIII, N43, pp. 371-375.

Rivarola, B. 1908. "La Revista. Su X año", Revista del Instituto Paraguayo, Vol XII, N59, pp. 469-472. 